\title{
Enantioselective HPLC-UV method for determination of eslicarbazepine acetate (BIA 2-093) and its metabolites in human plasma
}

\author{
Gilberto Alves, ${ }^{1}$ Isabel Figueiredo, ${ }^{1}$ Margarida Castel-Branco, ${ }^{1}$ Ana Loureiro, ${ }^{2}$ Ana Fortuna, \\ Amílcar Falcão ${ }^{1 *}$ and Margarida Caramona ${ }^{1}$ \\ 'Laboratory of Pharmacology, Faculty of Pharmacy, Coimbra University, 3000-141 Coimbra, Portugal \\ ${ }^{2}$ Department of Research and Development, BIAL, 4745-457 S. Mamede do Coronado, Portugal \\ Received 14 February 2007; accepted 13 March 2007
}

\begin{abstract}
Eslicarbazepine acetate (BIA 2-093) is a novel central nervous system drug undergoing clinical phase III trials for epilepsy and phase II trials for bipolar disorder. A simple and reliable chiral reversed-phase HPLC-UV method was developed and validated for the simultaneous determination of eslicarbazepine acetate, oxcarbazepine, $S$-licarbazepine and $R$-licarbazepine in human plasma. The analytes and internal standard were extracted from plasma by a solid-phase extraction using Waters Oasis ${ }^{\circledR}$ HLB cartridges. Chromatographic separation was achieved by isocratic elution with water-methanol $(88: 12$, v/v), at a flow rate of $0.7 \mathrm{~mL} / \mathrm{min}$, on a LichroCART $250-4$ ChiraDex $(\beta$-cyclodextrin, $5 \mu \mathrm{m})$ column at $30^{\circ} \mathrm{C}$. All compounds were detected at $225 \mathrm{~nm}$. Calibration curves were linear over the range $0.4-8 \mu \mathrm{g} / \mathrm{mL}$ for eslicarbazepine acetate and oxcarbazepine, and $0.4-80 \mu \mathrm{g} /$ $\mathrm{mL}$ for each licarbazepine enantiomer. The overall intra- and interday precision and accuracy did not exceed $15 \%$. Mean relative recoveries varied from 94.00 to $102.23 \%$ and the limit of quantification of the assay was $0.4 \mu \mathrm{g} / \mathrm{mL}$ for all compounds. This method seems to be a useful tool for clinical research and therapeutic drug monitoring of eslicarbazepine acetate and its metabolites $S$-licarbazepine, $R$-licarbazepine and oxcarbazepine. Copyright $@ 2007$ John Wiley \& Sons, Ltd.
\end{abstract}

KEYWORDS: eslicarbazepine acetate (BIA 2-093); oxcarbazepine; human plasma; bioanalytical method validation; enantioselective HPLC-UV method

\section{INTRODUCTION}

Until the last decade of the twentieth century, epileptic seizures were still managed by antiepileptic drugs (AEDs) such as carbamazepine (CBZ), phenytoin, valproic acid, ethosuximide, phenobarbital and some benzodiazepines (Levert et al., 2002). However, since the beginning of the 1990s, an explosion in knowledge about the neurobiology of epileptogenesis has taken place and several new AEDs have been introduced in clinical practice, such as vigabatrin, zonisamide, lamotrigine, gabapentin, felbamate, topiramate, tiagabine, oxcarbazepine (OXC) and levetiracetam (Bazil and Pedley, 1998; Ducan, 2002). Despite the currently available therapeutic arsenal of old and new AEDs, about $30 \%$ of epileptic patients are still not seizure-free, and

*Correspondence to: A. Falcão, Laboratory of Pharmacology, Faculty of Pharmacy, Coimbra University, 3000-141 Coimbra, Portugal. E-mail: acfalcao@ff.uc.pt

Abbreviations used: AED, antiepileptic drug; CBZ, carbamazepine; ESL, eslicarbazepine acetate; OXC, oxcarbazepine; $R$-LC, $R$ licarbazepine; $S$-LC, $S$-licarbazepine.

Contract/grant sponsor: Fundação para a Ciência e a Tecnologia, Programa POCTI; Contract/grant number: SFRH/BD/12694/2003.

Contract/grant sponsor: BIAL, Portugal. therefore, there is a substantial need to develop more effective drugs simultaneously with less potential for drug interactions and side effects (Deckers et al., 2003; Bialer, 2006).

Eslicarbazepine acetate (ESL) [S-(-)-10-acetoxy-10,11dihydro-5H-dibenz/b,f/azepine-5-carboxamide], previously known as BIA 2-093, is a novel chiral drug presently completing phase III clinical trials, as add-on therapy in refractory partial epilepsy, and undergoing phase II clinical trials, as monotherapy in partial epilepsy and in bipolar disorder (Almeida and Soares-da-Silva, 2007). ESL is chemically related to CBZ and OXC (Benes et al., 1999). CBZ is a very effective first-generation AED that is used as a major first-line drug for partial and generalized tonic-clonic seizures (Arroyo and Kramer, 2001; Coppola, 2004). In humans, the major metabolic pathway of CBZ is oxidation to carbamazepine-10,11epoxide, which seems to be responsible for several unwanted adverse effects and CBZ-related drug interactions resulting from the induction of hepatic microssomal cytochrome P450 enzymes (Myllynen et al., 1998; Arroyo and Kramer, 2001; Coppola, 2004). $\mathrm{OXC}$ is a second-generation CBZ, presenting a similar spectrum of anticonvulsant activity but showing a more favourable tolerability profile (Reinikainen et al., 1987; 
Schachter, 1999). Chemically, OXC differs from CBZ by a keto-group in the tenth position. Therefore, in humans, the achiral prodrug OXC is rapidly reduced in liver by cytosolic arylketone reductases to the pharmacologically active metabolite licarbazepine or 10-hydroxy-carbazepine (May et al., 2003; Flesch, 2004). Nevertheless, OXC first-pass reduction to licarbazepine is stereoselective, appearing in plasma as $S$ licarbazepine $(S$-LC) and $R$-licarbazepine $(R$-LC) in the enantiomeric ratio of approximately 4:1 (Flesch et al., 1992; Volosov et al., 1999). In fact, it is well known that enantiomers of chiral drugs may have different pharmacodynamic, pharmacokinetic and toxicological effects in biological systems (Misl'anová and Hutta, 2003). Accordingly, the enantiomeric dilution of the active metabolite of OXC is a negative aspect and the development of a single enantiomer (eutomer) or the manipulation of the enantiomeric ratio could be performed in order to optimize the therapeutic index. Thus, ESL, a third-generation $\mathrm{CBZ}$ or second-generation $\mathrm{OXC}$, was specifically designed to circumvent its further biotransformation to toxic metabolites, such as epoxides, and to avoid enantiomeric impurity and unnecessary production of enantiomers or diastereoisomers of its metabolites, without losing anticonvulsant potency (Benes et al., 1999; Hainzl et al., 2001). As a result, ESL exhibits a 'cleaner' metabolism and higher enantiomeric purity than OXC (Hainzl et al., 2001). Previous reports indicated that ESL is extensively metabolized to $S$-LC (95-98\%) and to a minor extent to $R$-LC and OXC (Almeida and Soares-da-Silva 2004; Almeida et al., 2005).

Over the years, several chromatographic methods for OXC and racemic licarbazepine determination have been developed (Noirfalise and Collinge, 1983; Menge et al., 1987; Elyas et al., 1990; Rouan et al., 1994; Pienimaki et al., 1995; Souppart et al., 2001; Levert et al., 2002; Mandrioli et al., 2003; Franceschi and Furlanut, 2005; Lanckmans et al., 2006). However, only three chiral HPLC assays have been validated to determine $S$ - and $R$-LC enantiomers, in which a very expensive column and mobile phase were employed (Flesch et al., 1992; Pichini et al., 1995; Volosov et al., 2000). ESL and its metabolites $S$-LC, $R$-LC and OXC have also been previously evaluated by a chiral HPLC-MS method, but it was not completely described (Hainzl et al., 2001; Almeida et al., 2005).

As ESL is a new drug in final phase of clinical trials, in our opinion it would be essential to develop and validate a simple chiral HPLC-UV method for simultaneous and stereoselective determination of ESL and its main metabolites in human plasma. Moreover, considering that epilepsy is a neurological disease with high prevalence and high incidence in patients younger than 1 year and older than 75 years (Arroyo and Kramer, 2001; Jarrar and Buchhalter, 2003), the availability of an easy-to-use HPLC-UV method is also imperative to achieve individualized dosage regimens and to improve the overall clinical outcomes by monitoring plasma drug concentrations in these special populations (Perucca, 2000; Johannessen et al., 2003; Neels et al., 2004).

The purpose of this paper is to describe an accurate, sensitive and practical enantioselective HPLC-UV assay to quantify ESL and its metabolites in human plasma, within a wide concentration range, which could be applied not only to clinical research but also to therapeutic drug monitoring.

\section{EXPERIMENTAL}

Chemicals and reagents. Standards of ESL (BIA 2-093, lot number 0000012976, 100\% pure by HPLC), $S$-LC (BIA 2-194, lot number PC020131B, 99.79\% pure by HPLC), $R$-LC (BIA 2-195, lot number PC040414, 100\% pure by HPLC), OXC (lot number 97.12.17, $>98 \%$ pure by HPLC) and BIA 2-265 (used as internal standard, lot number PC050704, 97.4\% pure by HPLC) were kindly supplied by BIAL (Porto, Portugal; Fig. 1). Methanol (HPLC grade, SDS), water milliQ (HPLC grade, >15 M $\Omega$, home-made), acetonitrile, ethyl acetate, sodium dihydrogen phosphate dihydrate, di-sodium hydrogen phosphate dehydrate and hydrochloric acid fuming $37 \%$ were purchased from Merck KGaA (Darmstadt, Germany). Drug-free human plasma from healthy donors was kindly provided by the Portuguese Blood Institute after the written consent of each subject.

\section{Chromatographic apparatus and conditions}

The HPLC system used for analysis was composed of a BAS480 liquid chromatograph equipped with a PM-80 pump, a Rheodyne manual injector with a $20 \mu \mathrm{L}$ loop, a BAS UV116 UV-vis detector, a BAS LC-22C temperature controller, a BAS DA-5 chromatography control and a data system interface (all from Bioanalytical Systems, West Lafayette, IN, USA). Data collection and integration were achieved by means of BAS Chromgraph Control and Chromgraph Report software version 2.30 .

The chromatographic separation of all four drugs and internal standard was carried out at $30^{\circ} \mathrm{C}$ by isocratic elution with water-methanol $(88: 12, \mathrm{v} / \mathrm{v})$, at a flow rate of $0.7 \mathrm{~mL} /$ min, on a LiChroCART 250-4 ChiraDex ( $\beta$-cyclodextrin, $5 \mu \mathrm{m})$ column protected by a LiChroCART 4-4 ChiraDex ( $\beta$-cyclodextrin, $5 \mu \mathrm{m}$ ) guard column purchased from Merck KGaA (Darmstadt, Germany). The mobile phase was filtered through a $0.45 \mu \mathrm{m}$ filter and degassed ultrasonically for 15 min before use. A sample volume of $20 \mu \mathrm{L}$ was injected and the analytes were detected at $225 \mathrm{~nm}$.

\section{Stock solutions, calibration standards and quality control samples}

The stock solutions of ESL $(2 \mathrm{mg} / \mathrm{mL}), S$-LC $(10 \mathrm{mg} / \mathrm{mL})$, $R$-LC $(10 \mathrm{mg} / \mathrm{mL})$, OXC $(2 \mathrm{mg} / \mathrm{mL})$ and internal standard $(1 \mathrm{mg} / \mathrm{mL})$ were prepared by dissolving appropriate amounts of each compound in acetonitrile. These solutions were 
<smiles>CC(=O)O[C@H]1Cc2ccccc2N(C(N)=O)c2ccccc21</smiles>

ESL<smiles>NC(=O)N1c2ccccc2C[C@H](O)c2ccccc21</smiles>

$S$-LC<smiles>NC(=O)N1c2ccccc2C[C@H](O)c2ccccc21</smiles>

$R$-LC<smiles>NC(=O)N1c2ccccc2CC(=O)c2ccccc21</smiles>

$\mathrm{OXC}$<smiles>NC(=O)N1c2ccccc2CC(CO)([N+](=O)[O-])c2ccccc21</smiles>

I.S. (BIA 2-265)

Figure 1. Chemical structures of eslicarbazepine acetate (ESL), $S$-licarbazepine $(S$-LC), $R$-licarbazepine ( $R$-LC), oxcarbazepine (OXC) and BIA 2-265 used as internal standard (IS).

adequately diluted with acetonitrile in order to give $S$-LC and $R$-LC $2 \mathrm{mg} / \mathrm{mL}$ solutions and ESL, $S$-LC, $R$-LC and OXC $200 \mu \mathrm{g} / \mathrm{mL}$ solutions. The stock and working solutions were used appropriately to afford five combined spiking solutions of all four drugs with final concentrations of 10, 50, 500, 1000 and $2000 \mu \mathrm{g} / \mathrm{mL}$ for $S$-LC and $R$-LC and 10, 20, 50, 100 and $200 \mu \mathrm{g} / \mathrm{mL}$ for ESL and OXC. An internal standard working solution of $200 \mu \mathrm{g} / \mathrm{mL}$ was prepared by diluting appropriately the respective stock solution. All standard solutions were stored at approximately $4^{\circ} \mathrm{C}$ and protected from light for one month, except the internal standard working solution, which was prepared daily.

Calibration standards at $0.4,0.8,2,4$ and $8 \mu \mathrm{g} / \mathrm{mL}$ for ESL and $\mathrm{OXC}$ and at $0.4,2,20,40$ and $80 \mu \mathrm{g} / \mathrm{mL}$ for $S$-LC and $R$-LC were prepared by adding known amounts of the appropriate combined spiking solutions to blank human plasma. Quality control (QC) samples were prepared independently in the same matrix (blank human plasma).

\section{Extraction procedure}

Aliquots of human plasma $(250 \mu \mathrm{L})$ were added to $750 \mu \mathrm{L}$ of $0.1 \mathrm{M}$ sodium phosphate buffer $(\mathrm{pH} 5)$ spiked with $10 \mu \mathrm{L}$ of the internal standard working solution. The samples were vortex-mixed and loaded into Oasis ${ }^{\circledR}$ HLB (30 mg, $1 \mathrm{~mL}$ ) cartridges (Waters, Milford, MA, USA), which were previously conditioned with $1 \mathrm{~mL}$ of methanol, $1 \mathrm{~mL}$ of acetonitrile and $1 \mathrm{~mL}$ of water-acetonitrile $(95: 5, \mathrm{v} / \mathrm{v})$. After sample elution, the loaded cartridges were submitted to $-30 \mathrm{kPa}$ and washed twice with $1 \mathrm{~mL}$ of water and twice with $1 \mathrm{~mL}$ of water-acetonitrile (95:5, v/v). After drying the sorbent under airflow for $5 \mathrm{~min}$, the analytes were eluted with $1 \mathrm{~mL}$ of ethyl acetate under gentle vacuum and then the cartridges were dried for $30 \mathrm{~s}$ at $-30 \mathrm{kPa}$. The eluates were evaporated to dryness under a nitrogen stream at $45^{\circ} \mathrm{C}$ and the residues reconstituted in $100 \mu \mathrm{L}$ of HPLC mobile phase, vortexed for approximately $30 \mathrm{~s}$ and placed in an ultrasonic bath at room temperature for approximately $1 \mathrm{~min}$. Following this, the reconstituted extracts were transferred to $0.22 \mu \mathrm{m}$ Spin-X centrifugal filters, centrifuged at $13,400 \mathrm{rpm}$ for $2 \mathrm{~min}$ and $20 \mu \mathrm{L}$ of the final filtered samples were injected onto the HPLC system.

\section{Method validation}

The method was validated according to the general recommendations published in the last few years concerning to bioanalytical method validation and acceptance criteria for validation parameters: selectivity, linearity, sensitivity, precision, accuracy, sample dilution, recovery and stability (Shah et al., 2000; Peters and Maurer, 2002).

Method selectivity. The extracts of blank human plasma samples from six different subjects were tested for endogenous interferences. Furthermore, solutions of several commonly co-prescribed AEDs such as phenobarbital, phenytoin, carbamazepine, valproic acid, felbamate, gabapentin, vigabatrin, lamotrigine, topiramate and levetiracetam, and solutions of non-AED cotherapies including antidepressants (dothiepin, mirtazapine, sertraline, trazodone, escitalopram and paroxetine), anxiolytics or hypnotics (diazepam, cloxazolam, lorazepam and ethyl loflazepate) and antipsychotics (risperidone, olanzapine, chlorpromazine and zuclopenthixol) were also injected to check for drugs which could potentially interfere with eslicarbazepine acetate and its metabolites.

Calibration curve. The linearity of the analytical method was assessed by using calibration standards at five different 
concentrations within the range of $0.4-8 \mu \mathrm{g} / \mathrm{mL}$ for ESL and OXC and $0.4-80 \mu \mathrm{g} / \mathrm{mL}$ for $R$-LC and $S$-LC. Calibration curves were constructed by plotting drug-internal standard peak height ratio as a function of the respective concentrations in the calibration samples. The data were subjected to a weighted linear regression analysis using $1 / x^{2}$ as weighting factor, which was chosen taking the plots and the sums of absolute percentage relative error into account (Almeida et al., 2002). The sensitivity was evaluated by determining the limit of quantification (LOQ), which is defined as the lowest concentration of the calibration curve that can be measured with acceptable inter- and intraday precision and accuracy, assessed respectively by the coefficient of variation (CV) and the deviation from nominal value (bias) within $20 \%$. The limit of detection (LOD), defined as the lowest concentration that can be distinguished from the noise level, was determined for ESL and its metabolites by analysing plasma samples with known concentrations, after successive dilutions, and was established by visual evaluation of the minimum level at which the analytes can be reliably detected.

Precision and accuracy. Intra- and interday precision and accuracy were assessed by using QC samples in replicate at three different concentration levels representative of all calibration ranges $(n=5)$. The concentrations tested were 0.4 , 4 and $8 \mu \mathrm{g} / \mathrm{mL}$ for ESL and OXC and $0.4,40$ and $80 \mu \mathrm{g} / \mathrm{mL}$ for each licarbazepine enantiomer. The acceptance criterion, for precision, was a CV within $15 \%$ (or $20 \%$ in the LOQ) and, for accuracy, a bias within $15 \%$ (or $20 \%$ in the LOQ).

Sample dilution. Dilution effect (1:10) was also investigated with QC samples at $40 \mu \mathrm{g} / \mathrm{mL}$ for ESL and OXC and at $400 \mu \mathrm{g} / \mathrm{mL}$ for $R$-LC and $S$-LC to ensure that plasma samples exceeding the highest concentration of the calibration range could be diluted with blank human plasma and accurately quantified. The precision and accuracy of the diluted QC samples were determined in both intra- and interday assays $(n=5)$.

Recovery. The relative recovery from human plasma was calculated at $0.4,4$ and $8 \mu \mathrm{g} / \mathrm{mL}$ for ESL and OXC and at 0.4 , 40 and $80 \mu \mathrm{g} / \mathrm{mL}$ for licarbazepine enantiomers $(n=5)$. The absolute recovery of the internal standard was also evaluated at the concentration used in sample analysis. The relative recoveries of the analytes were calculated by comparing the analyte-internal standard peak height ratios for extracted samples with the corresponding ratios obtained with nonextracted standards that represent $100 \%$ of recovery. The absolute recovery of the internal standard was also determined by calculating the peak height ratio of the internal standard in extracted samples and non-extracted standards.

Stability. Human plasma stability of ESL and its metabolites was assessed, at low and high concentration levels, by $24 \mathrm{~h}$ at $4^{\circ} \mathrm{C}$ and 30 days at $-30^{\circ} \mathrm{C}$ to simulate sample handling and storage time in the freezer before analysis $(n=5)$. Stability was assessed by comparing the data of QC samples analyzed before (reference samples) and after being exposed to the conditions for stability assessment (stability samples). The stability sample/reference sample ratios of $85-115 \%$ were accepted as stability criterion.

\section{RESULTS}

\section{Chromatographic separation and selectivity}

The separation of $R$-LC, $S$-LC, OXC, ESL and internal standard in spiked human plasma was achieved successfully using the chromatographic conditions and the solid-phase extraction (SPE) procedure previously described. Under these analytical conditions the last-eluting analyte was ESL, with a retention time of approximately $24 \mathrm{~min}$, and the order of elution was internal standard, $R$-LC, $S$-LC, OXC and ESL, respectively.

Representative chromatograms of the extracts of blank and spiked human plasma samples are shown in Fig. 2. The lack of response in blank human plasma samples at internal standard and analytes retention times was demonstrated at $225 \mathrm{~nm}$. Likewise, none of the possibly co-prescribed drugs or commonly prescribed AED cotherapies tested interfered with the internal standard or analytes.

\section{Calibration curve}

The calibration curves obtained in human plasma from five calibration standards were linear for ESL and $\mathrm{OXC}$ in the range of $0.4-8 \mu \mathrm{g} / \mathrm{mL}$ and for licarbazepine enantiomers in the range of $0.4-80 \mu \mathrm{g} / \mathrm{mL}$. Respectively, the regression equations of calibration curves were $y=0.0547 x+0.0005\left(r^{2}=0.993\right)$ for ESL, $y=0.1609 x-0.0061\left(r^{2}=0.998\right)$ for OXC, $y=0.1320 x$ $-0.0005\left(r^{2}=0.998\right)$ for $R$-LC and $y=0.1086 x-0.0009$ $\left(r^{2}=0.998\right)$ for $S$-LC. These results demonstrated a good linearity $\left(r^{2}>0.99\right)$ between peak height ratios and concentrations. The LOQ of the assay was set at $0.4 \mu \mathrm{g} / \mathrm{mL}$ for all analytes with acceptable precision and accuracy (Table 1), and the LOD was $0.1 \mu \mathrm{g}$ / $\mathrm{mL}$ for ESL and $0.04 \mu \mathrm{g} / \mathrm{mL}$ for OXC, $R$-LC and $S$-LC.

\section{Precision and accuracy}

Precision and accuracy data for intra and interday QC plasma samples are presented in Table 1 . The overall intra- and interday CV value was $\leq 9.25 \%$. Intra- and interday bias varied between -0.56 and $4.98 \%$. These data indicated that the developed HPLC method is reproducible and accurate, given that neither CV nor bias exceeded $15 \%$ (or $20 \%$ in the LOQ), in agreement with literature recommendations. The precision and accuracy of the diluted plasma samples varied from 0.89 to $2.63 \%$ and from -1.96 to $0.38 \%$, respectively. These results revealed that a 10 -fold dilution with blank human plasma can be rightly applied if the concentration of a trial sample exceeds the highest concentration of the calibration curve. 

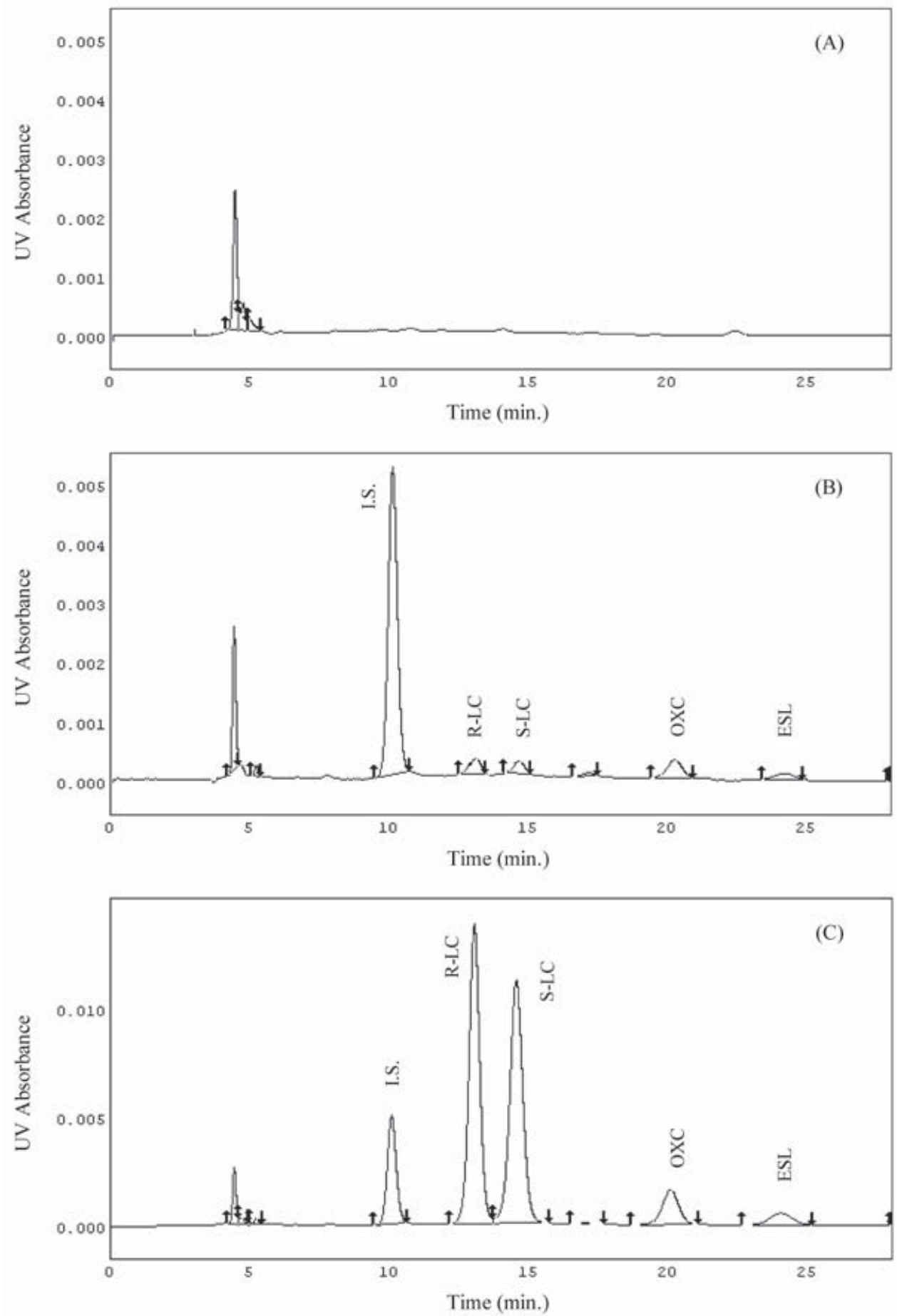

Figure 2. Typical chromatograms of extracted human plasma: (A) blank human plasma; (B) human plasma spiked with internal standard (IS) (concentration $=8 \mu \mathrm{g} / \mathrm{mL}$ ), $R$ licarbazepine $(R$-LC), $S$-licarbazepine $(S$-LC), oxcarbazepine (OXC) and eslicarbazepine acetate $(\mathrm{ESL})$ (concentration $=0.4 \mu \mathrm{g} / \mathrm{mL})$; $(\mathrm{C})$ human plasma spiked with IS (concentration $=8 \mu \mathrm{g} / \mathrm{mL}$ ), $R$-LC and $S$-LC (concentration $=20 \mu \mathrm{g} / \mathrm{mL}$ ), OXC and ESL (concentration = $2 \mu \mathrm{g} / \mathrm{mL}$ ); (D) human plasma spiked with IS (concentration $=8 \mu \mathrm{g} / \mathrm{mL}$ ), $R$-LC and $S$-LC (concentration $=80 \mu \mathrm{g} / \mathrm{mL}), \mathrm{OXC}$ and ESL (concentration $=8 \mu \mathrm{g} / \mathrm{mL}$ ). 


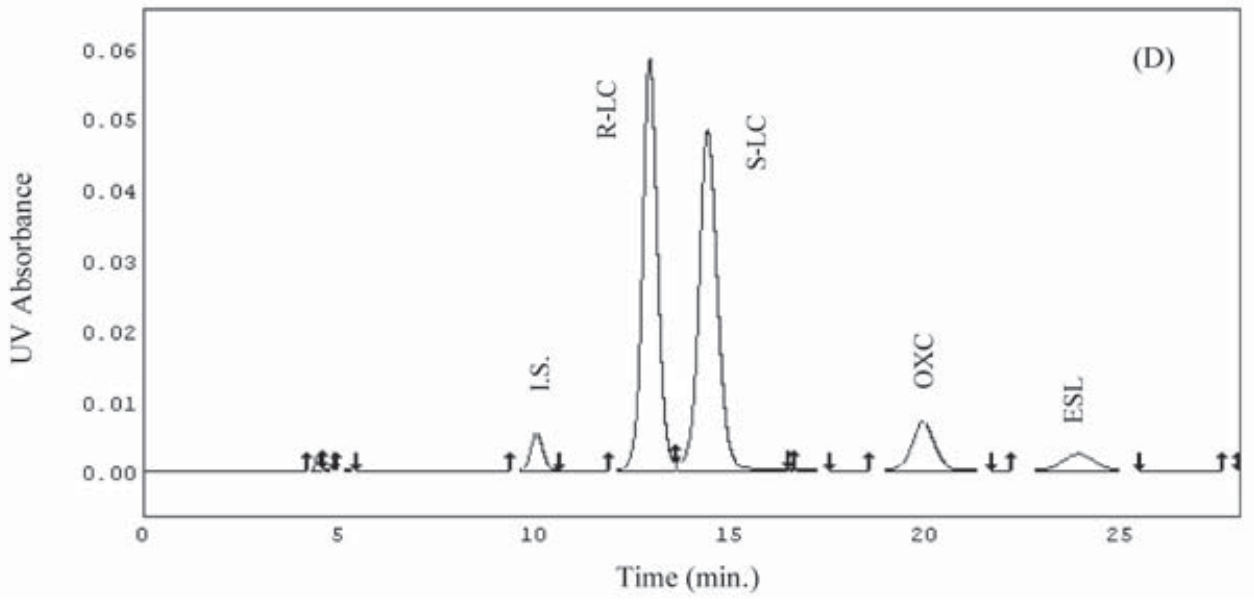

Figure 2. (Continued)

Table 1. Intra- and interday precision (CV, \%) and accuracy (bias, \%) for the simultaneous determination of eslicarbazepine acetate (ESL), oxcarbazepine (OXC), S-licarbazepine (S-LC) and $R$-licarbazepine $(R-L C)$ in human plasma $(n=5)$

\begin{tabular}{|c|c|c|c|c|c|c|c|c|}
\hline \multirow[b]{3}{*}{$C_{\text {Nominal }}{ }^{\mathrm{a}}$} & \multicolumn{8}{|c|}{ Assay } \\
\hline & \multicolumn{4}{|c|}{ Intraday } & \multicolumn{4}{|c|}{ Interday } \\
\hline & $\mathrm{CV} \%$ & Bias \% & $\mathrm{CV} \%$ & Bias \% & $\mathrm{CV} \%$ & Bias \% & $\mathrm{CV} \%$ & Bias \% \\
\hline Plasma & \multicolumn{2}{|c|}{ ESL } & \multicolumn{2}{|c|}{$\mathrm{OXC}$} & \multicolumn{2}{|c|}{ ESL } & \multicolumn{2}{|c|}{$\mathrm{OXC}$} \\
\hline 0.4 & 5.52 & 1.65 & 6.22 & 2.53 & 9.25 & 1.23 & 2.63 & 1.70 \\
\hline 4 & 1.24 & 0.39 & 1.65 & 0.36 & 2.86 & -0.56 & 1.20 & -0.54 \\
\hline \multirow[t]{2}{*}{8} & 1.91 & 3.42 & 2.16 & 4.05 & 0.98 & 1.97 & 0.91 & 3.60 \\
\hline & \multicolumn{2}{|c|}{$S$-LC } & \multicolumn{2}{|c|}{$R$-LC } & \multicolumn{2}{|c|}{$S$-LC } & \multicolumn{2}{|c|}{$R$-LC } \\
\hline 0.4 & 4.10 & 1.18 & 3.21 & 1.02 & 6.26 & 0.11 & 4.22 & 0.49 \\
\hline 40 & 1.92 & 0.76 & 1.85 & 0.50 & 2.57 & -0.38 & 2.60 & -0.09 \\
\hline 80 & 1.99 & 4.98 & 1.98 & 4.22 & 0.97 & 3.29 & 1.00 & 3.05 \\
\hline
\end{tabular}

${ }^{a}$ Nominal concentration $(\mu \mathrm{g} / \mathrm{mL}) ; \mathrm{CV}$, coefficient of variation.

\section{Recovery}

The relative drug recoveries from human plasma are presented in Table 2. The mean relative recoveries, taking ESL and its metabolites into account, ranged from 92.36 to $102.85 \%$ and showed low $\mathrm{CV}$ values. The absolute recovery of the internal standard was $84.99 \%$, with a CV of $2.78 \%$. All average recoveries calculated are high and reproducible, either for analytes or internal standard.

Table 2. Relative recovery (\%) of eslicarbazepine acetate (ESL), oxcarbazepine (OXC), $S$-licarbazepine (S-LC) and $R$-licarbazepine $(R-L C)$ in human plasma

\begin{tabular}{|c|c|c|c|c|c|}
\hline \multirow[b]{2}{*}{$C_{\text {Nominal }}{ }^{\mathrm{a}}$} & \multirow[b]{2}{*}{$n$} & \multicolumn{4}{|c|}{ Relative recovery } \\
\hline & & Mean $(\%)$ & $\mathrm{CV}(\%)$ & Mean (\%) & CV (\%) \\
\hline Plasma & & \multicolumn{2}{|c|}{ ESL } & \multicolumn{2}{|c|}{$\mathrm{OXC}$} \\
\hline 0.4 & 5 & 90.10 & 8.06 & 85.78 & 3.27 \\
\hline 4 & 5 & 100.00 & 1.87 & 94.36 & 1.71 \\
\hline \multirow[t]{3}{*}{8} & 5 & 101.16 & 1.98 & 96.93 & 2.26 \\
\hline & 15 & 97.09 & 6.67 & 92.36 & 5.71 \\
\hline & & \multicolumn{2}{|c|}{$S$-LC } & \multicolumn{2}{|c|}{$R$-LC } \\
\hline 0.4 & 5 & 97.36 & 5.38 & 102.09 & 4.71 \\
\hline 40 & 5 & 104.09 & 1.38 & 104.99 & 1.24 \\
\hline \multirow[t]{2}{*}{80} & 5 & 101.57 & 1.33 & 101.49 & 1.30 \\
\hline & 15 & 101.01 & 4.22 & 102.85 & 3.25 \\
\hline
\end{tabular}

${ }^{\mathrm{a}}$ Nominal concentration $(\mu \mathrm{g} / \mathrm{mL}) ; n$, number of samples; $\mathrm{CV}$, coefficient of variation. 


\section{Stability}

From the stability data obtained at 0.8 and $4 \mu \mathrm{g} / \mathrm{mL}$ for ESL and OXC and at 2 and $40 \mu \mathrm{g} / \mathrm{mL}$ for $S$-LC and $R$-LC no significant loss was observed when spiked plasma samples were stored for $24 \mathrm{~h}$ at $4^{\circ} \mathrm{C}$ or for 1 month at $-30^{\circ} \mathrm{C}$. Thus, ESL, OXC and both licarbazepine enantiomers were revealed to be stable in the assayed conditions.

\section{DISCUSSION}

The present paper describes the first reversed-phase HPLC-UV-SPE chiral assay fully validated to quantify ESL and its main metabolites $S$-LC, $R$-LC and OXC in human plasma. This HPLC method appears to be accurate, precise and sensitive in assessing ESL and its metabolites in human plasma, but its major advantages involve the very simple chromatographic conditions. Unlike the methods previously published by Flesch et al. (1992), Pichini et al. (1995) and Volosov et al. (2000) concerning to independent quantification of licarbazepine enantiomers, this enantioselective assay was carried out on reversed-phase using a safe and economical mobile phase essentially composed of water. In the preceding methods, the analysis took place on normal-phase chromatographic columns using more expensive, pollutant and toxic mobile phases, such as $n$-hexane:2-propanol, $n$-hexane:ethanol or $n$-hexane:ethanol:2-propanol. Besides the specific chromatographic conditions, the SPE procedure used here in sample pretreatment offers many other benefits over the traditional liquid-liquid extraction methods, such as faster sample preparation, lower cost, greater recoveries, less sample handling, improved safety and easy automation (Soriano et al., 2001; Camel, 2003). Even though ESL and its metabolites could be analyzed using MS detection systems (Hainzl et al., 2001; Almeida et al., 2005), most hospitals and laboratories are not equipped with such high-cost instruments (Velpandian et al., 2004; Janchawee et al., 2007). Therefore, the availability of the current method will be important and it may be easily adopted to perform clinical studies. Among the several strategies to separate enantiomers, the enantiomeric resolution of $S$-LC and $R$-LC was achieved by the easiest of them, direct HPLC using a chiral stationary phase composed of $\beta$ cyclodextrins bounded covalently to silica gel.

Thus, the present method seems to be a useful tool to individually assess the pharmacologically active metabolites licarbazepine enantiomers and their prodrugs ESL and OXC. The wide working range tested, as well as all the other advantages previously referred to, will allow its application not only in the support of clinical trials but also in the routine therapeutic drug monitoring assays or in bioequivalence studies that involve the new antiepileptic drug ESL and the already marketed OXC.

\section{Acknowledgments}

This work was supported by Fundação para a Ciência e a Tecnologia, Programa POCTI (SFRH/BD/12694 2003), Portugal and by BIAL, Portugal. The authors would like to thank the Portuguese Blood Institute for help in obtaining drug-free human plasma from healthy donors.

\section{REFERENCES}

Almeida AM, Castel-Branco MM and Falcão AC. Linear regression for calibration lines revisited: weighting schemes for bioanalytical methods. Journal of Chromatography B 2002; 774: 215-222.

Almeida L and Soares-da-Silva P. Safety, Tolerability, and pharmacokinetic profile of BIA 2-093, a novel putative antiepileptic, in a rising multiple-dose study in young healthy humans. Journal of Clinical Pharmacology 2004; 44: 906-918.

Almeida L and Soares-da-Silva P. Eslicarbazepine acetate (BIA 2-093). Neurotherapeutics 2007; 4: 88-96.

Almeida L, Falcão A, Maia J, Mazur D, Gellert M and Soaresda-Silva P. Single-dose and steady-state pharmacokinetics of eslicarbazepine acetate (BIA 2-093) in healthy elderly and young subjects. Journal of Clinical Pharmacology 2005; 45: 1062-1066.

Arroyo S and Kramer G. Treating Epilepsy in the Elderly: Safety Considerations. Drug Safety 2001; 24: 991-1015.

Bazil CW and Pedley TA. Advances in medical treatment of epilepsy. Annual Review of Medicine 1998; 49: 135-162.

Benes J, Parada A, Figueiredo AA, Alves PC, Freitas AP, Learmonth DA, Cunha RA, Garrett J and Soares-da-Silva P. Anticonvulsant and sodium channel-blocking properties of novel 10,11-dihydro-5hdibenz[b,f]azepine-5-carboxamide derivatives. Journal of Medicinal Chemistry 1999; 42: 2582-2587.

Bialer M. New antiepileptic drugs that are second generation to existing antiepileptic drugs. Expert Opinion on Investigational Drugs 2006; 15: 637-647.

Camel V. Solid phase extraction of trace elements. Spectrochimica Acta Part B 2003; 58: 1177-1233.

Coppola G. Treatment of partial seizures in childhood: an overview. CNS Drugs 2004; 18: 133-156.

Deckers CLP, Genton P, Sills GJ and Schmidt D. Current limitations of antiepileptic drug therapy: a conference review. Epilepsy Research 2003; 53: 1-17.

Duncan JS. The promise of new antiepileptic drugs. British Journal of Clinical Pharmacology 2002; 53: 123-131.

Elyas AA, Goldberg VD and Patsalos PN. Simple and rapid microanalytical high-performance liquid chromatographic technique for the assay of oxcarbazepine and its primary active metabolite 10hydroxycarbazepine. Journal of Chromatography 1990; 528: 473-479.

Flesch G. Overview of the clinical pharmacokinetics of oxcarbazepine. Clinical Drug Investigation 2004; 24: 185-203.

Flesch G, Francotte E, Hell F and Degen PH. Determination of the $R-(-)$ and $S-(+)$ enantiomers of the monohydroxylated metabolite of oxcarbazepine in human plasma by enantioselective highperformance liquid chromatography. Journal of Chromatography 1992; 581: 147-151.

Franceschi L and Furlanut M. A simple method to monitor plasma concentrations of oxcarbazepine, carbamazepine, their main metabolites and lamotrigine in epileptic patients. Pharmacological Research 2005; 51: 297-302.

Hainzl D, Parada A and Soares-da-Silva P. Metabolism of two new antiepileptic drugs and their principal metabolites $S(+)$ - and $R(-)$ 10,11-dihydro-10-hydroxy carbamazepine. Epilepsy Research 2001; 44: $197-206$. 
Janchawee B, Keawpradub N, Chittrakarn S, Prasettho S Wararatananurak $\mathrm{P}$ and Sawangjareon K. A high-performance liquid chromatographic method for determination of mitragynine in serum and its application to a pharmacokinetic study in rats. Biomedical Chromatography 2007; 21: 176-183.

Jarrar RG and Buchhalter JR. Therapeutics in pediatric epilepsy, part 1: the new antiepileptic drugs and the ketogenic diet. Mayo Clinic Proceedings 2003; 78: 359-370.

Johannessen SI, Battino D, Berry DJ, Bialer M, Kramer G, Tomson $\mathrm{T}$ and Patsalos PN. Therapeutic Drug Monitoring of the Newer Antiepileptic Drugs. Therapeutic Drug Monitoring 2003; 25: 347363.

Lanckmans K, Clinckers R, Eeckhaut AV, Sarre S, Smolders I and Michotte Y. Use of microbore LC-MS/MS for the quantification of oxcarbazepine and its active metabolite in rat brain microdialysis samples. Journal of Chromatography B 2006; 831: 205-212.

Levert H, Odou P and Robert H. Simultaneous determination of four antiepileptic drugs in serum by high-performance liquid chromatography. Biomedical Chromatography 2002; 16: 19-24.

Mandrioli R, Ghedini N, Albani F, Kenndler E and Raggi MA. Liquid chromatographic determination of oxcarbazepine and its metabolites in plasma of epileptic patients after solid-phase extraction. Journal of Chromatography B 2003; 783: 253-263.

May TW, Korn-Merker E and Rambeck B. Clinical pharmacokinetics of oxcarbazepine. Clinical Pharmacokinetics 2003; 42: 1023 1042.

Menge GP, Dubois JP and Bauer G. Simultaneous determination of carbamazepine, oxcarbazepine and their main metabolites in plasma by liquid chromatography. Journal of Chromatography 1987; 414: 477-483.

Misl'anová $\mathrm{C}$ and Hutta M. Role of biological matrices during the analysis of chiral drugs by liquid chromatography. Journal of Chromatography B 2003; 797: 91-109.

Myllynen P, Pienimaki P, Raunio H and Vahakangas K. Microsomal metabolism of carbamazepine and oxcarbazepine in liver and placenta. Human \& Experimental Toxicology 1998; 17: 668-676.

Neels HM, Sierens AC, Naelaerts K, Scharpé SL, Hatfield GM and Lambert WE. Therapeutic drug monitoring of old and newer antiepileptic drugs. Clinical Chemistry and Laboratory Medicine 2004; 42: $1228-1255$.

Noirfalise A and Collinge A. Quantitative determination of oxcarbazepine. Journal of Chromatography 1983; 274: 417-420.

Perucca E. Is there a role for therapeutic drug monitoring of new anticonvulsants? Clinical Pharmacokinetics 2000; 38: 191-204.

Peters FT and Maurer HH. Bioanalytical method validation and its implications for forensic and clinical toxicology-a review. Accreditation and Quality Assurance 2002; 7: 441-449.

Pichini S, Altieri I, Passa AR, Zuccaro P and Pacifi R. Stereoselective bioanalysis of oxcarbazepine and the enantiomers of its metabolites by high-performance liquid chromatography. Journal of Liquid Chromatography 1995; 18: 1533-1541.

Pienimaki P, Fuchs S, Isojarvi J and Vahakangas K. Improved detection and determination of carbamazepine and oxcarbazepine and their metabolites by high-performance liquid chromatography. Journal of Chromatography B 1995; 673: 97-105.

Reinikainen KJ, Keranen T, Halonen $\mathrm{T}$, Komulainen $\mathrm{H}$ and Riekkinen PJ. Comparison of oxcarbazepine and carbamazepine: a double-blind study. Epilepsy Reseach 1987; 1: 284-289.

Rouan MC, Decherf M, Le Clanche V, Lecaillon JB and Godbillon J. Automated microanalysis of oxcarbazepine and its monohydroxy and transdiol metabolites in plasma by liquid chromatography. Journal of Chromatography B 1994; 658: 167-172.

Schachter SC. Oxcarbazepine: current status and clinical applications. Expert Opinion on Investigational Drugs 1999; 8: 1103-1112.

Shah VP, Midha KK, Findlay JWA, Hill HM, Hulse JD, McGilveray IJ, McKay G, Miller KJ, Patnaik RN, Powell ML, Tonelli A, Viswanathan CT and Yacobi A. Bioanalytical method validationa revisit with a decade of progress. Pharmaceutical Research 2000; 17: $1551-1557$.

Soriano T, Jurado C, Menéndez M and Repetto M. Improved solidphase extraction method for systematic toxicological analysis in biological fluids. Journal of Analytical Toxicology 2001; 25: 137-143.

Souppart C, Decherf M, Humbert H and Maurer G. Development of a high throughput 96-well plate sample preparation method for the determination of trileptal (oxcarbazepine) and its metabolites in human plasma. Journal of Chromatography B 2001; 762: 9-15.

Velpandian T, Mathur R, Agarwal NK, Arora B, Kumar L and Gupta SK. Development and validation of a simple liquid chromatographic method with ultraviolet detection for the determination of imatinib in biological samples. Journal of Chromatography B 2004, 804: 431-434.

Volosov A, Xiaodong S, Perucca E, Yagen B, Sintov A and Bialer M. Enantioselective pharmacokinetics of 10-hydroxycarbazepine after oral administration of oxcarbazepine to healthy Chinese subjects. Clinical Pharmacology \& Therapeutics 1999; 66: 547-553.

Volosov A, Bialer M, Xiaodong S, Perucca E, Sintov A and Yagen B. Simultaneous stereoselective high-performance liquid chromatographic determination of 10-hydroxycarbazepine and its metabolite carbamazepine-10,11-trans-dihydrodiol in human urine. Journal of Chromatography B 2000; 738: 419-425. 